\title{
LA DEMOCRACIA INTERNA DE LOS PARTIDOS POLÍTICOS
}

\author{
RUBÉN HERNÁNDEZ VALLE \\ Profesor Ordinario de Derecho Constitucional \\ Universidad de San José de Costa Rica
}




\section{SUMARIO}

I. INTRODUCCIÓN. II. FUnción DE LOS PARTIDOS POLITICOS DENTRO DEL SISTEMA DEMOCRATICO. III. EL PRINCIPIO DEMOCRÁTICO Y SU APLICACIÓN EN EL AMBITO ELECTORAL. IV. CONCEPTO DE DEMOCRATIZACION INTERNA DE LOS PARTIDOS POLITICOS. V. EL CONTENIDO DE LA DEMOCRATIZACIÓN INTERNA DE LOS PARTIDOS POLITICOS. 1. La escogencia de los dirigentes internos. 2. La designación de los candidatos a puestos electivos. 3. La determinación de la plataforma política. 4. La financiación de las tendencias de los partidos políticos. 5. La representación equitativa en las papeletas por género. 6 . El control heterónomo de constitucionalidad y de legalidad sobre la actividad interna de los partidos políticos. 


\title{
LA DEMOCRACIA INTERNA DE LOS PARTIDOS POLÍTICOS
}

POR

\author{
RUBÉN HERNÁNDEZ VALLE \\ Profesor Ordinario de Derecho Constitucional \\ Universidad de San José de Costa Rica
}

\section{INTRODUCCIÓN}

La regulación constitucional de los partidos políticos es un fenómeno relativamente reciente ${ }^{1}$, por lo que gran parte de sus principios fundamentales no han sido todavía desarrollados por las diferentes legislaciones. Uno de ellos, tal vez el más importante en la etapa actual de la evolución de los partidos políticos, es el relativo a su democratización interna, el cual ha sido poco analizado a nivel legislativo y carente de estudio doctrinario sistemático.

En el presente trabajo trataré de delimitar el concepto jurídicopolítico de la democratización interna y esbozar sus principales contenidos, tomando como marco de referencia el ordenamiento costarricense, aunque desde luego haré alusión a otras legislaciones.

\section{FUNCIÓN DE LOS PARTIDOS POLÍTICOS DENTRO DEL SISTEMA DEMOCRÁTICO}

La aparición de los partidos políticos marca un hito trascendental en el mundo occidental, pues hace posible la transición de un con-

1 Garcia de LA GuARDiA, J. M.: Régimen constitucional de los partidos politicos, Caracas, 1987, págs. 183-195. 
trol oligárquico-burgués del poder a la democracia constitucional moderna. Justamente se ha dicho que la democracia actual es una democracia de partidos y la invención más importante en el campo de la organización política². Inclusive en los sistemas de gobiernos autocráticos, los partidos políticos tienen una importancia decisiva. Como decía Laski, aquí las elecciones son similares a las carreras de caballos en que participa un solo caballo. No obstante, los partidos políticos o más bien el partido oficial constituye el centro de poder político más importante del Estado.

Es claro entonces que los partidos políticos colaboran en la formación y expresión de la voluntad política del pueblo. Por ello han sido definidos como "asociaciones de ciudadanos que con ayuda de su propia organización aspiran a influir en un determinado sentido sobre la formación de la voluntad del Estado" ${ }^{3}$. De lo anterior se deduce que los partidos tienen una base corporativa, pues siempre estarán integrados por ciudadanos en el ejercicio de su derechos de asociación, con una organización que actualiza la participación social de sus miembros. Además, son portadores, normalmente, de una determinada ideología o, al menos, de un conjunto de creencias más o menos definido sobre los diferentes aspectos de la vida política, social, económica, etc.

Por tanto, los partidos políticos cumplen cuatro funciones básicas: a) seleccionan a los futuros líderes: b) mantienen contacto entre el gobierno (oposición incluida) y la gente en general; c) representan los diversos grupos de la comunidad y d) integran tanto esos grupos como sea posible. Lo anterior tiene origen en la necesidad de las comunidades organizadas cooperativamente (comunidades políticas) de recoger parte de sus miembros y situarlos en organizaciones que decidan los rumbos alternativos de la decisión y acción política del Estado4.

En efecto, detrás de cada partido existen asociaciones y grupos sociales organizados formal o informalmente. Estos grupos son expresión y representan las diferentes opiniones o intereses de los individuos en torno a un determinado número de criterios o ideas. Los partidos, por su propia naturaleza, aspiran a refundir los criterios de las

2 Zampetti, Dallo Stato liberale allo Stato dei Partiti, Milano, 1973, págs. 1-19.

3 Tribunal Constitucional Alemán, citado por STEIN, Derecho Político, Madrid, 1983, pág. 155.

4 Friederich, C. J., Gobierno constitucional y demociacia, Madrid, 1975, tomo II, págs. 357-358. 
asociaciones $y$ grupos que los apoyan. De esta forma cada partido cuenta con el apoyo de determinados sectores de la sociedad e intenta imponer su voluntad asi integrada frente a la de los otros sectores de la sociedad. Por consiguiente, los partidos se esfuerzan, en primer lugar, por obtener el favor de los electores y, después, en el seno del gobierno, por influir sobre la actividad del Estado. Recordemos que Heller, con justa razón, decía que todo poder político, por su propia naturaleza y por vocación existencial, aspira a convertirse en poder estatal 5 .

\section{EL PRINCIPIO DEMOCRÁTICOY SU APLICACIÓN EN EL ÁMBITO ELECTORAL}

El principio democrático tiene gran relevancia dentro del ámbito del Derecho Electoral, pues constituye uno de sus fundamentos jurídico-políticos más importantes.

La democracia es un principio general de la Constitución y, por lo tanto, del ordenamiento. Hay que recordar, antes de seguir adelante, que los principios, al igual que las reglas, pueden clasificarse en materiales y estructurales. Estos últimos, a su vez, se subdividen en procedimentales y organizativos.

El principio democrático se despliega normativamente tanto en su dimensión material (derechos fundamentales) como en su dimensión estructural, tanto organizativa como procedimental (división de poderes, composición y elección de órganos representativos, etc. ${ }^{6}$. La dimensión estructural del principio democrático, que es la que aquí nos interesa, está referida a las garantías procedimentales u organizativas tanto del Estado como en el ámbito de organizaciones no estatales, pero que tienen una gran relevancia publica, como es justamente el caso de los partidos políticos.

Dentro de este orden de ideas, la jurisprudencia de la Sala Constitucional costarricense ha dicho que «el principio democrático que inspira nuestra organización política y social debe impregnar la actividad de los partidos políticos, que, a pesar de la deficiente regulación con que cuentan, son entidades de derecho publicon' 7 .

5 Heller, H., Teoría del Estado, México, 1955, págs. 499 y ss.

6 Aragón Reyes, M., Constitución y democracia, Madrid, 1989, pág. 104.

7 Sala Constitucional, Voto 2150-92. 
El artículo 95 de la Constitución costarricense dispone, en lo conducente que "La ley regulará el ejercicio del sufragio de acuerdo con los siguientes principios:.. 8) Garantias para la designación de autoridades y candidatos de los partidos políticos, según los principios democráticos y sin discriminación por género». El numeral 98 , que es el expresamente constitucionaliza los partidos políticos establece, en su segundo párrafo lo siguiente: «Los partidos políticos expresaran el pluralismo político, concurrirán a la formación y manifestación de la voluntad popular y serán instrumentos fundamentales para la participación política. Se creación y el ejercicio de su actividad serán libres dentro del respeto la Constitución y la ley. Su estructura interna y funcionamiento deberán ser democráticos».

Ambas normas constitucionales, junto con el artículo 96 ibidem que regula la contribución estatal de los partidos políticos, configuran el marco normativo fundamental para la aplicación del principio democrático a la organización y funcionamiento de los partidos políticos en Costa Rica.

\section{CONCEPTO DE DEMOCRATIZACIÓN INTERNA DE LOS PARTIDOS POLITICOS}

Entendemos por democratización interna de los partidos politicos todo aquel conjunto de disposiciones normativas y medidas políticas tendentes a garantizar que: a) la escogencia de los dirigentes internos; b) la designación de los candidatos a puestos de elección popular; c) la determinación de la plataforma política sean el resultado de la voluntad mayoritaria de los miembros del partido y no la imposición de las cúpulas políticas o económicas; d) regular la financiación de las tendencias al interno de los partidos; e) garantizar, asimismo, la representación proporcional por género y f) tutelar los derechos fundamentales de los miembros del partido mediante la existencia de un control heterónomo de constitucionalidad y legalidad sobre la actividad interna de los partidos.

Para comprender cabalmente el planteamiento anterior hay que tomar en cuenta que los partidos políticos son estructuras complejas, junto a las cuales como totalidad intervienen tres factores sociales diferentes: a) los miembros del partido; b) los órganos del partido; c) el pueblo. Por tal razón es necesario analizar sus relaciones con sus miembros, con sus órganos internos y con el pueblo. 


\section{Los partidos y sus miembros}

Los partidos políticos son factores de integración. Por ello una de sus funciones primarias es la de formar concepciones políticas unitarias, a partir de las diferentes opiniones que cada uno de sus adherentes tiene sobre lo que debe ser la conducción del Estado $y$, en segundo lugar, intentar llevarlas a la práctica. Por tanto, su estructura interna debe ser integradora, es decir, debe hacer prevalecer la totalidad frente a la parte.

De lo anterior se deduce que no puede existir una libertad irrestricta para participar en un partido ni para permanecer dentro de él. La capacidad de funcionamiento de los partidos "y muchas veces, inclusive, su existencian depende de que puedan mantener alejadas o puedan separar a aquellas personas o grupos de miembros que perturban la ejecución de su línea política unitaria. Desde luego que esto no significa que la incorporación a un partido político pueda ser rechazada arbitrariamente, lo mismo que la determinación de su expulsión. Ambas situaciones, a fin de compaginarlas con una auténtica libertad de asociación, base esencial de los partidos políticos, sólo deben producirse cuando el solicitante o el militante, en su caso, supongan un peligro para la existencia o funcionamiento del partido, ya sea porque no reconozca sus Estatutos o sus principios politicos, o bien porque determinados hechos hagan suponer que no cumplirá aquellos, o porque su actuación haya violado los principios fundamentales del partido.

\section{Los partidos y sus órganos}

Las decisiones en los partidos políticos se toman por mayoría. Este principio se aplica, lógicamente, a la integración de sus órganos y a la formación de su voluntad. Por tanto, los partidos políticos deben organizarse en tal forma que sus órganos ejecuten su voluntad y no el partido la voluntad de sus órganos, como ocurre con harta frecuencia. Debe quedar claro que la primacía en la unidad del partido sobre la individualidad de sus miembros no significa el dominio de un equipo director, sino más bien la supremacia de la mayoría. La voluntad sobre quien debe dirigir el partido y sobre lo que es vinculante para él debe formarse de abajo hacia arriba. Sobre los mecanismos idóneos al efecto volveremos con más detalle más adelante. 


\section{Los partidos y el pueblo}

Aunque en principio los partidos tienden a realizar sus concepciones ideológicas y programáticas a través del poder estatal, es claro también que no son sólo asociaciones de intereses ni que representan únicamente los intereses personales de sus miembros, sino que deben estar orientados hacia la comunidad e intentar realizar el bien común desde su perspectiva particular. En última instancia los gobernantes representan al pueblo $y$, por tanto, deben pretender la realiza- . ción de los intereses de toda la comunidad, aunque deban su mandato a un partido político.

Resulta evidente, entonces, que las vinculaciones entre los representantes políticos y su partido están reguladas por normas internas de los propios partidos, lo que hace necesario establecer mecanismos idóneos para garantizar el verdadero ejercicio de la democracia interna de los partidos.

\section{EL CONTENIDO DE LA DEMOCRATIZACIÓN INTERNA DE LOS PARTIDOS POLITIICOS}

La democratización interna de los partidos políticos está históricamente ligada a seis aspectos: 1) la escogencia de los dirigentes internos; 2 ) la designación de los candidatos a puestos electivos; 3) la determinación de la plataforma política; 4) garantizar la financiación de las tendencias; 5) la representación equitativa en las papeletas por género, y 6) el control heterónomo de constitucionalidad y legalidad de la actividad interna de los partidos.

\section{La escogencia de los dirigentes internos}

En esta materia ha prevalecido normalmente el criterio de que los dirigentes internos deben nombrarse de manera oligárquica, o bien mediante procedimientos en los que participan sólo determinados sectores del partido.

Otra forma que ha permitido también a las cúpulas mantener el control interno de los partidos ha sido el establecimiento de requisitos muy estrictos para acceder a tales cargos. Con ello se han enseñoreado pequeñas argollas dentro de los partidos. 
No obstante, en algunos países existen reacciones contra la concentración del poder interno de los partidos en unas pocas manos. Para ello se han ideado mecanismos de nombramiento abiertos y democráticos. Por ejemplo, la escogencia de Secretarios Generales y otros funcionarios se realiza mediante elecciones populares en las que votan todos los miembros de los partido que previamente hayan dado su adhesión.

También se tiende a flexibilizar los requisitos exigidos para acceder a puestos de dirección dentro del partido, tales como haber ejercido previamente el cargo de congresista, senador, Ministro, etc., o haber sido miembro del partido por numerosos años, porque son mecanismos que impiden el acceso de las nuevas generaciones a los cargos directivos dentro de los partidos.

Con estas nuevas medidas juridico-políticas se prohíja una apertura más democrática de los partidos y se permite que cualquiera de sus adherentes, que se sienta con capacidad para ello, someta su nombre al electorado de su partido. En esta forma se pueden quebrar las monolíticas cúpulas de poder que, la mayoria de las veces, se enquistan en los partidos no por capacidad sino más bien por compadreos o por militancia vegetativa.

En Costa Rica, por mandato constitucional expreso, los partidos políticos están obligados a escoger democráticamente a sus dirigentes. Sin embargo, faltan regulaciones legales a nivel nacional y estatutarias al interno de los partidos que ejecuten puntualmente dicho principio constitucional.

\section{La designación de los candidatos a puestos electivos}

Es evidente que la designación a dedo de los candidatos a puestos de elección popular ha pasado a ser una reminiscencia histórica en todos los países con algún grao de madurez electoral.

A fin de permitir que la designación de los candidatos a puestos de elección popular se haga con la mayor participación posible de miembros del partido, se han implementado dos sistemas: a) las llamadas Convenciones o Asambleas y b) las Elecciones Primarias.

\section{a) Las Convenciones o Asambleas}

Bajo este sistema los candidatos son elegidos por un pequeño grupo de miembros delegados que supuestamente representan a los 
distintos sectores sociales, económicos y políticos que conforman el partido. La forma de elegir esos representantes varía, pues a veces se hace mediante votaciones cerradas entre los distintos grupos que de interés que representa el partido (cooperativas, sindicatos, asociaciones profesionales, sector empresarial, etc.). Otras veces se realizan votaciones populares desde el nivel de distrito, en las que se nombran delegados en circunscripciones territoriales más grandes $y$, así sucesivamente, hasta llegar a conformar una Asamblea (Convención) a nivel nacional.

Como el sistema de votación es indirecto, con gran frecuencia los candidatos electos no resultan ser los que apoyan las bases del partido, sino más bien los que han logrado influenciar a los miembros de la Convención, ya sea por pactos o dádivas, o bien porque son impuestos por la cúpula del partido.

\section{b) Las Elecciones Primarias}

Esta modalidad de elección se ha desarrollado con gran éxito en Estados Unidos de América, donde encontramos dos versiones: las Primarias abiertas y las Primarias cerradas. En el primer sistema el votante puede escoger la papeleta de cualquier partido y no está obligado a declarar a cuál de ellos pertenece. En las Primarias cerradas, en cambio, el elector debe declarar a cuál partido pertenece y solicitar la papeleta del partido de sus preferencias. Si su pertenencia al partido es puesta en duda, entonces debe jurar que en la elección anterior dio el voto a ese partido. En Costa Rica, donde se sigue la modalidad de las Primarias cerradas, el elector debe llenar una fórmula de adhesión al partido antes de emitir su voto.

Ambos sistemas presentan serios defectos en la práctica, pues el primero permite a los partidos contrarios interferir en la designación para favorecer a aquellos candidatos más vulnerables electoralmente, en tanto que el segundo viola el principio del voto secreto.

Otro grave problema de las Primarias es la relación que existe entre ellas y las sucesivas votaciones. La mayor parte de las legislaciones establece que el precandidato que obtenga la mayoría relativa de votos en la Primaria, será declarado el candidato ganador. Con este sistema puede ocurrir que un representante de la minoría resulte electo candidato con sólo obtener una mayoría relativa entre varios precandidatos. Para eliminar este inconveniente se han utilizado tres modalidades: 
i) La Convención post-Primaria, mediante la cual la designación se hace por medio de la Convención (Asamblea de delegados), cuando ningún candidato obtenga un determinado porcentaje de la votación.

ii) El sistema de voto preferencial, que consiste en que cada elector debe expresar un voto preferente por un segundo candidato y de tal voto se hará uso si ninguno de los candidatos obtiene mayoria absoluta.

iii) Las segundas primarias (run off), que funcionan cuando ninguno de los candidatos obtiene una mayoría suficiente y se recurre a una segunda votación, limitada sólo a los dos candidatos que obtuvieron más votos en la primera vuelta.

Los tres sistemas presentan graves inconvenientes. EI primero porque desemboca en una Convención; el segundo porque la experiencia ha demostrado que la mayoría de los electores omite expresar su preferencia en la primera vuelta y el tercero porque implica cuantiosos gastos y obliga a los electores a ir a las urnas de votación tres veces.

iv) En Uruguay primero y en una ocasión en Honduras, surgió una cuarta posibilidad, según la cual las Primarias se celebran simultáneamente con las elecciones generales. En esta forma los partidos presentan diversas precandidaturas dentro de la respectiva casilla, resultando vencedor el partido que obtenga la mayoría exigida por la legislación electoral y elegido como Presidente el precandidato del partido vencedor que obtenga el mayor número de votos.

Algunos paises, como Honduras y Costa Rica más recientemente, han introducido la celebración de Primarias para escoger también a los candidatos a diputados y a concejales municipales.

En el caso costarricense, por ejemplo, la distribución de la lista de los candidatos a diputados electos popularmente, se debe añadir la distribución de los puestos tomando en cuenta el género, que por mandato legal es del $40 \%$ como mínimo para la mujeres. De esa forma cada partido político ha diseñado un sistema propio. Por ejemplo, en el PUSC el aspirante debe obtener al menos el $40 \%$ de los votos de su distrito electoral para ser elegido; caso contrario, la Asamblea del partido escoge entre los candidatos que hayan obtenido más votos.

Este sistema tiende a evitar las negociaciones posteriores entre la tendencia triunfadora y las perdedoras, a fin de obtener algunos can- 
didatos a los cargos de diputados y concejales municipales, dado que esa forma de elección refleja en forma más equitativa la conformación de fuerzas al interno del partido.

En la praxis, sin embargo, el sistema presenta graves inconvenientes, puesto que aquellos aspirantes con mayores recursos económicos terminan, casi siempre, venciendo en las elecciones Primarias.

No obstante, si se desea que las Primarias sirvan como un medio auténticamente democrático de elegir a los candidatos a los cargos de elección popular, especialmente a los candidatos a la Presidencia, es necesario rodearlas de una serie de garantías efectivas a fin de que todas las tendencias tengan igualdad de oportunidades para alcanzar la postulación.

Entre tales medidas deberian, establecerse, en nuestro criterio, las siguientes: a) prohibición de que los Secretarios Generales y todas aquellas otras personas que ocupan cargos dirigentes de relevancia dentro del partido, durante los tres años anteriores a la celebración de una Primaria, puedan postular sus nombres como precandidatos a la Presidencia de la República, con lo que se evita que un precandidato utilice la maquinaria del partido en su beneficio personal; b) la propaganda debe limitarse no sólo en tiempo sino también en cantidad, de manera que los precandidatos tengan igual acceso a los medios de comunicación; c) el transporte, el día de las elecciones, deberá estar en manos del partido y no de las tendencias, a fin de que no haya desigualdades por razones económicas; además, es ilógico que miembros de un mismo partido tengan que poner a funcionar flotillas de vehículos independientes, y d) utilizar parte de la financiación estatal que reciben los partidos con el fin de financiar los gastos de organización, censo y recolección del voto de las distintas tendencias.

Sólo si tales mecanismos se implantan es posible hablar de que las Primarias se realizan en igualdad de condiciones, de manera que salga elegido el más apto y no el que tenga más recursos económicos, como sucede con harta frecuencia.

La experiencia ha demostrado que el sistema de Primarias presenta algunos inconvenientes, entre los que cabe citar: a) complica las operaciones electorales, imponiendo un notable aumento en los gastos; b) favorece el abstencionismo en las votaciones, polarizando el interés de los electores sobre las competencias personales; c) aumenta los gastos de propaganda de cada candidato, favoreciendo, en consecuencia, a los que cuentan con mayor apoyo económico; d) finalmente, fomenta las luchas internas en el seno de los partidos. 
Por todas estas razones, las Primarias no han podido realizar su principal objetivo: sustraer la designación de los candidatos a la influencia de las hegemonias oligárquicas del partido. No obstante, es el sistema más democrático que se conoce para la elección de los candidatos a puestos de elección popular.

\section{La determinación de la plataforma política}

El problema más grave es el relativo a la influencia que tienen las Primarias sobre la línea ideológico-programática del partido. En realidad, todo sistema de designación no sólo debe responder al fin de favorecer a los aspirantes más idóneos en el seno del partido, sino que, además, debe satisfacer la exigencia de que sea garantizada la adhesión de los candidatos designados a la corriente ideológico-programática del partido. Por tal motivo, los Estatutos de los partidos europeos establecen la exigencia de que ninguna persona puede ser elegida como candidato si no ha sido militante activo del partido durante un determinado número de años antes de su postulación ${ }^{8}$.

En cambio, en el sistema de las Primarias directas no sólo basta la simple inscripción al partido para postularse como precandidato, sino que la determinación del programa electoral es realizada por órganos del partido a los que con frecuencia no pertenecen los futuros candidatos.

Para resolver tales problemas, en Estados Unidos se han adoptado diversas soluciones:

\section{a) Celebración de Convenciones para la elaboración de programas (plataform)}

Sólo en algunos pocos Estados las Convenciones preceden a las Primarias, porque hay escasas posibilidades de que el programa sea aceptado por los candidatos designados. Normalmente la Convención encargada de preparar el programa se realiza después de las Primarias, pero en tales Convenciones los delegados terminan generalmente por aceptar el programa del candidato vencedor, aunque sea expo-

8 Sobre el particular, véase VIRGA, P., // Partito Político nell'ordinamento giuridico, Milano, 1948, pág. 235. 
nente de una corriente minoritaria, ya que éste difícilmente acepta un programa diferente del suyo, aunque provenga de la mayoría de los delegados.

\section{b) Determinación del programa por parte de un Comité Privado (Party Council)}

Este Comité está formado, no sólo por los candidatos designados, sino además por algunos senadores y congresistas electos en las anteriores elecciones. Es un sistema preferible al precedente, porque atribuye en definitiva la aprobación del programa a quienes deberán eventualmente ejecutarlo. No se elimina todavia el inconveniente de que los candidatos designados, pertenecientes a una corriente de minoría, puedan imponer un programa que no sea de la aceptación de la mayoría.

Es evidente, entonces, que el programa de Gobierno debe ser congruente con la ideología que sustenta el partido, pues de lo contrario los gobernantes pierden credibilidad. Por ello la forma más democrática de establecer la plataforma política de un partido sería mediante la celebración de una Convención en la que estuvieran representados los diferentes grupos de intereses que conforman el espectro electoral del partido. No obstante, esta solución presenta el inconveniente de que casi nunca los delegados a esas Convenciones son posteriormente los encargados, en los órganos deliberativos y ejecutivos del Gobierno, de ejecutar el programa de gobierno.

En la praxis, sin embargo, el programa de gobierno es el que redacta el grupo asesor del candidato presidencial, tomando en cuenta la coyuntura política, económica y social que se presenta al momento de la campaña electoral, lo cual implica, en numerosas ocasiones, que dicho programa sea abiertamente incompatible con la ideología que sustenta oficialmente el partido.

\section{La garantía de financiación de las tendencias internas de los partidos políticos}

Es un hecho empiricamente demostrado que el resultado de las modernas campañas políticas, en las que se dan a conocer a los electores las personalidades y los programas de los partidos en competencia, está esencialmente determinado por el efecto de la propagan- 
da de los partidos sobre cada elector. Esta actividad, junto con la organización para el día de los comicios y la actividad proselitista durante la campaña, demandan una gran cantidad de dinero, que los partidos deben obtener de alguna parte. Los mismos principios son aplicables a las tendencias internas de los partidos.

Los mismos principios son aplicables a las tendencias internas de los partidos políticos.

Tradicionalmente la financiación de los partidos provenía de dos fuentes: a) las cuotas de los afiliados y b) las contribuciones de carácter voluntario general. A medida que fueron aumentando los gastos y las necesidades de las campañas, las contribuciones corrían el peligro de causar un grado serio de dependencia en cuanto a las preferencias personales de cada gran donante, si es que no se iba directo a la corrupción de sus ideales.

Para remediar estos males se han tomado, en general, tres medidas específicas: a) la publicidad de los estados financieros de los partidos; b) la financiación parcial por parte del Estado de las campañas políticas, y c) el control y límite de las contribuciones privadas.

\section{a) La publicidad de los estados financieros}

Algunas legislaciones anglosajonas - como la inglesa y la de algunos Estados norteamericanos - han sido pioneras en este campo, al imponer la obligación a los partidos de hacer públicos sus presupuestos, a fin de permitir que sus adherentes, los órganos estatales y, en general, todos los ciudadanos puedan ejercitar un control sobre las fuentes de financiación del partido y la forma en que tales dineros se invierten.

Modernamente, algunas legislaciones latinoamericanas, como la colombiana y la argentina, han introducido nuevos mecanismos de control, tendentes a lograr que haya un efectivo control estatal y de los ciudadanos sobre las finanzas de los partidos.

Entre tales medidas de control se encuentran la obligación de los partidos de llevar registros contables, conforme a las reglas de contabilidad generalmente aceptadas. Estos libros son autorizados por los tribunales electorales.

Anualmente deben presentarse estados contables, debidamente auditados por un contador público, acerca de los ingresos y 
egresos de los partidos ante los Tribunales o Consejos Electorales. Asimismo, esos estados contables se publican en el Diario Oficial y quedan a disposición del público en general durante el lapso de tres meses, a fin de que cualquier ciudadano pueda revisarlos y hacerles las observaciones que juzgue pertinentes.

Asimismo se establecen severas sanciones penales para quienes falsifiquen comprobantes y los registros contables de los partidos.

\section{b) Regulación de la financiación privada}

La idea latente detrás del establecimiento de controles y limites a las contribuciones privadas se fundamenta en la preocupación de que a través de tales contribuciones a los partidos, se pudieren camuflar tentativas de corrupción respecto de los futuros gobernantes ${ }^{9}$.

Es innegable, por otra parte, que las personas y grupos que contribuyen a la financiación de un determinado partido, esperan obtener luego alguna retribución si sus candidatos resultaren electos. Esta influencia económica puede y suele ser muy dañina para los gobiernos democráticos, pues atenta contra el principio de representación nacional.

Para evitar la excesiva injerencia de personas o grupos económicamente poderosos, o bien de dineros provenientes del lavado de dólares o de las actividades ligadas al narcotráfico, las distintas legislaciones han establecido, entre otras, las siguientes regulaciones en la materia:

i) Se prohija la financiación de los partidos preferentemente mediante pequeñas contribuciones estables o periódicas de sus adherentes.

ii) Se establecen límites máximos para los contribuciones privadas. Estos montos se actualizan periódicamente para ajustarlos a las tasas de inflación. Verbigracia, el artículo 176 bis del Código electoral costarricense establece como límite de las contribuciones privadas anuales el equivalente a cuarenta y cinco veces el salario base mínimo menor men-

9 Dicen dos autores norteamericanos sobre el particular: whe line between bribary and payment for election-day services is a hardone to draW", MERRIAM-GosNELL, The American Party System, Nueva York, 1940, pág. 362. 
sual que figure en la Ley de Presupuesto Ordinario de la República vigente en el momento de la contribución.

iii) Se prohíben las contribuciones de sociedades y otras personas jurídicas nacionales, con el fin de evitar que se utilicen cascarones jurídicos para evadir los límites establecidos a las personas físicas. Además, en múltiples ocasiones resulta imposible establecer quién es el verdadero dueño de una persona jurídica colectiva.

iv) Se prohiben las contribuciones de extranjeros, tanto de personas físicas como jurídicas. Curiosamente, en Costa Rica se autoriza a que tales personas puedan realizar contribuciones o donaciones dedicadas específicamente a labores de capacitación, formación e investigación de los partidos políticos.

v) Las personas físicas que contribuyan a los partidos políticos deben declarar, bajo la fe del juramento, las fuentes de sus ingresos. Esto con el fin de evitar contribuciones indeseables o la utilización de testaferros. Si el contribuyente miente, entonces podrá ser procesado por el delito de falsedad ideológica.

\section{c) La contribución estatal}

En contra de la financiación de las campañas políticas por parte del Estado se ha argumentado que no es compatible con el principio de libre formación de la voluntad y de la opinión pública, pues ésta debe ser absolutamente independiente de la actuación del Estado. Se ha dicho, también, dentro de este mismo orden de ideas, que aunque la contribución parcial de los partidos políticos no supone su incorporación a la esfera estatal, sin embargo es evidente que su ámbito de libertad queda seriamente limitado ${ }^{10}$.

A tales objeciones basta con oponer el irrefutable argumento del Tribunal Constitucional Español de que "las elecciones constituyen una función pública cuya ejecución obliga a los órganos estatales constitucionales. Éstos se hallan obligados a crear las condiciones necesarias para el desarrollo de las elecciones. Debido a la importancia fun- 
damental que los partidos tienen en relación con el proceso electoral, está justificado que se les proporcionen los medios para hacer frente a los gastos necesarios para una adecuada campaña electoral " $"$.

En Costa Rica, por ejemplo, existe una profusa regulación sobre la financiación estatal de las campañas electorales.

Entre sus principios fundamentales se encuentran los siguientes: a) la contribución estatal no puede exceder del $0,19 \%$ del producto interno bruto del año trasanterior a la celebración de la elección para Presidente, Vicepresidentes de la República y Diputados a la Asamblea Legislativa; b) este porcentaje se destina a cubrir los gastos que genere la participación de los partidos políticos en esos procesos electorales, y satisfacer las necesidades de capacitación y organización política. Cada partido político fija los porcentajes correspondientes a estos rubros; c) tienen derecho a recibir la contribución estatal, los partidos políticos que alcancen al menos un $4 \%$ de los sufragios válidamente emitidos a escala nacional o los inscritos a escala provincial, que obtuvieren como mínimo ese porcentaje en la provincia o eligieren, por lo menos, un Diputado; d) previo otorgamiento de las cauciones correspondientes, los partidos políticos tienen derecho a que se les adelante parte de la contribución estatal; e) para recibir el aporte del Estado, los gastos de los partidos políticos deben ser comprobados por el Tribunal Supremo de Elecciones.

Hace falta, sin embargo, que la contribución estatal se extienda a nivel de los partidos municipales, así como también a las luchas de tendencias. Justamente, como indicamos en su oportunidad, una de las grandes desventajas que presentan las Primarias estriba justamente en que normalmente triunfan los candidatos con mayor apoyo económico, lo que atenta directamente contra el principio de democratización interna.

\section{La representación equitativa en las papeletas por género}

Durante los últimos años, producto de la corriente doctrinaria que aboga por el establecimiento de acciones afirmativas para evitar la discriminación de las mujeres en el ámbito político, se ha promulgado legislación que obliga a los partidos a que tanto su cúpula inter- 
na como sus candidatos a puestos de elección popular respeten el principio de la representación equitativa por género.

En Costa Rica, por ejemplo, al menos el $40 \%$ de los candidatos a diputados y a regidores municipales deben ser mujeres. Por jurisprudencia, elTribunal Supremo de Elecciones estableció que al menos una de las dos candidaturas a Vicepresidentes de la República debe ser ocupada por una mujer ${ }^{12}$.

Sin embargo, dicho principio puede hacerse nugatorio si no se establece un mecanismo efectivo para que la representación proporcional por género se haga en puestos elegibles. Para ello, cada partido, por lo general, establece mecanismos propios, algunos de los cuales tienden a favorecer a los candidatos varones.

Dentro de los sistemas conocidos, pareciera que el más equitativo es el seguido por la SPD alemana, según el cual los puestos dentro de las papeletas electorales se asignan alternativamente hombre, mujer, hombre, y así sucesivamente, o bien mujer, hombre, mujer y asi sucesivamente, dependiendo del precandidato que obtuvo más votos en las Primarias. Verbigracia, si el precandidato más votado fue un hombre, entonces la lista será encabezada por un varón; por el contrario, si el precandidato más votado fue una mujer, entonces la lista electoral será encabezada por la precandidata del sexo femenino que obtuvo más votos.

\section{El control heterónomo de constitucionalidad y legalidad sobre la actividad interna de los partidos políticos}

El Estado de Derecho que vive la gran mayoría de las naciones modernas reclama que la majestad del Derecho sea la que impere en el seno interno de los partidos políticos $y$ no el humor cambiante de los dirigentes de turno.

Dentro de este orden de ideas, es necesario que actos tales como la expulsión de miembros del partido, las resoluciones de los órganos internos, etc., puedan ser controlados externamente, ya sea por órganos de naturaleza judicial o bien por los propios Tribunales electorales.

12 Tribunal Supremo de Elecciones, resolución 1544-E-2001 de las 8 h. 40 m. del 24 de julio del 2001. 
En el Derecho Comparado se conocen hoy día tres sistemas de justicia electoral: a) el contencioso de jurisdiccional constitucional; b) el contencioso de jurisdicción ordinaria, y c) el contencioso mixto.

En el primer sistema se asigna el control de los actos electorales a la jurisdicción constitucional. Por ejemplo, en Austria, Francia y España.

En el segundo sistema, los tribunales ordinarios son competentes para conocer los conflictos de carácter electoral. Tal modalidad es utilizada en Inglaterra, Canadá y Estados Unidos. En América Latina se utiliza en Argentina, México y Paraguay. Sin embargo, en los tres primeros países los órganos jurisdiccionales conviven con órganos administrativos electorales autónomos ${ }^{13}$.

Finalmente, el sistema mixto, propio de América Latina, asigna la resolución de los conflictos electorales a órganos especializados, que pueden ser de naturaleza jurisdiccional o administrativa. Se pueden citar los casos de Uruguay y Costa Rica.

El control heterónomo de constitucionalidad y legalidad sobre la actividad interna de los partidos políticos tiende a garantizar, de manera efectiva, que los derechos de los miembros de un partido político son respetados por los órganos dirigentes.

13 OROzco, Jesús, "El Contencioso Electoral / La Calificación Electoral», en Tratado de Derecho Electoral Comparado de América Latina, México, 1998, pág. 727. 